\title{
Laboreal
}

Volume $14 \mathrm{~N}^{\circ} 2$ | 2018

Digitalização e evolução do trabalho real

\section{Concepción en diseño industrial y arquitectura: deseo, pertinencia, cooperación y cognición}

Texto original: Lebahar, J.-Ch. (2007). La conception en design industriel et en architecture. Désir, pertinence, coopération et cognition (pp. 15-21). Paris: Hermes-Lavoisier.

A conceção em design industrial e em arquitetura: desejo, pertinência, cooperação e cognição

La conception en design industriel et en architecture : désir, pertinence, coopération et cognition

The conception in industrial design and architecture: desire, pertinence, cooperation and cognition

\section{Jean-Charles Lebahar}

Traductor: Nicolás Canales Bravo

\section{(2) OpenEdition}

\section{Journals}

\section{Edición electrónica}

URL: http://journals.openedition.org/laboreal/707

DOI: $10.4000 /$ laboreal.707

ISSN: 1646-5237

\section{Editor}

Universidade do Porto

\section{Referencia electrónica}

Jean-Charles Lebahar, « Concepción en diseño industrial y arquitectura: deseo, pertinencia, cooperación y cognición », Laboreal [En línea], Volume 14 №2 | 2018, Publicado el 01 diciembre 2018, consultado el 24 septiembre 2020. URL : http://journals.openedition.org/laboreal/707 ; DOI : https:// doi.org/10.4000/laboreal.707

Este documento fue generado automáticamente el 24 septiembre 2020.

Laboreal está licenciado com uma Licença Creative Commons - Atribuição-NãoComercial 4.0 Internacional. 


\section{Concepción en diseño industrial y arquitectura: deseo, pertinencia, cooperación y cognición}

Texto original: Lebahar, J.-Ch. (2007). La conception en design industriel et en architecture. Désir, pertinence, coopération et cognition (pp. 15-21). Paris: Hermes-Lavoisier.

A conceção em design industrial e em arquitetura: desejo, pertinência, cooperação e cognição

La conception en design industriel et en architecture : désir, pertinence, coopération et cognition

The conception in industrial design and architecture: desire, pertinence, cooperation and cognition

Jean-Charles Lebahar

Tradución : Nicolás Canales Bravo

\section{REFERENCIA}

Texto original: Lebahar, J.-Ch. (2007). La conception en design industriel et en architecture. Désir, pertinence, coopération et cognition (pp. 15-21). Paris: HermesLavoisier

\section{Introducción}

1 El hombre diseña y utiliza artefactos, es decir objetos artificiales, desde las palabras que emplea para dibujar las cosas o comunicar sus pensamientos, hasta los ordenadores portátiles, pasando por una peineta, la pintura que tiñe y protege los muros de una casa; la casa misma, o la ley que se ejerce ante la injusticia. Para H.A. Simon, este hecho 
es una evidencia: 'el mundo donde hoy vivimos es cada vez más un mundo artificial, hecho por el hombre, que un mundo natural. Casi todos los elementos de nuestro entorno muestran la evidencia del artificio humano' (Simon, 1991, p. 2).

2 La actividad de diseño se puede definir como la construcción y la comunicación de un modelo de artefacto que no resulta de la réplica de un modelo existente. Esta construcción 'cognitiva' está basada en conocimientos y en el uso que hacen los profesionales (arquitectos, diseñadores, dibujantes, ingenieros, etc.) para producir las informaciones que definen los atributos del nuevo artefacto (las formas de una carrocería de automóvil, las funciones de un ordenador portátil, la estética de un edificio, la ergonomía de un control remoto). Para simular, evaluar y comunicar estas informaciones, estos sujetos establecen representaciones que son expresados bajo la forma de modelos: dibujos, objetos geométricos, maquetas, imágenes digitales, sistemas de símbolos, etc.

3 Los análisis de la actividad agrupados en este libro, bajo la forma de estudio de casos, están centrados sobre un sujeto psicológico que concibe artefactos, un 'sujetodiseñador' (SD), dentro del dominio de la arquitectura y del diseño industrial, ya sea en una situación operacional o didáctica.

Generalmente, una tarea de diseño se encuentra prescrita bajo la forma de una 'mando de artefacto'. Esta constituye un estado inicial de la representación del artefacto a concebir, y puede ser comunicada a un SD de formas diferentes (a través de especificaciones redactadas según las normas industriales; una discusión entre un arquitecto y su cliente, un profesor que entrega un ejercicio de proyecto a un alumno; una reunión de creatividad reuniendo uno o muchos diseñadores, convocados por un agente comercial y/o un fabricante industrial, con el fin de elaborar el concepto de un nuevo producto, etc.). El estado inicial de la representación del artefacto contenido en una orden, provee al SD informaciones más o menos completas, más o menos precisas, más o menos seguras, y más o menos ciertas, sobre este artefacto.

5 En otros términos, el SD no puede satisfacerse solo y de forma inmediata de esas informaciones para comprender el problema que impone la elaboración y la comunicación de la representación definitiva del artefacto: el modelo que permitirá su realización material (planos de ejecución, una maqueta sólida o digital, etc.).

6 Este modelo tiene como función guiar las acciones de aquellos que serán encargados de realizarla, en una obra en construcción o en una fábrica, usando máquinas o cualquier tipo de engranaje. Un modelo de este tipo debe definir, con la menor ambigüedad posible, un artefacto que esté en conformidad con ciertas exigencias. Sin embargo, si los atributos del artefacto representado originalmente en la orden constituyen, bajo la forma de prescripciones, un fin o un deseo para los autores de esta orden, ellos no constituyen un fin o un deseo para el SD, a menos que él los asimile a un estado deseado de artefacto.

7 Este estado despende de sus conocimientos, de los medios de concepción de los cuales dispone cuando ha sido solicitado, de sus afinidades o de su desinterés para ciertos artefactos o para ciertas tecnologías. Éste depende igualmente de esquemas imaginarios que persiguen al SD, y también de valores éticos y estéticos que defiende con más o menos intransigencia o diplomacia, con más o menos emoción. Estos diferentes aspectos justifican el enfoque multidisciplinar. 
8 El SD es un objeto de conocimiento abstracto-concreto, construido para describir estos diferentes aspectos: un sujeto psicológico, pero igualmente histórico que concibe artefactos. Empíricamente, el SD es siempre un objeto concreto y observable, un profesional confrontado a una tarea identifica como practicante un oficio bajo condiciones particulares (asalariado de una gran empresa, responsable de una agencia en situación liberal, experimentado o debutante, especializado o no, etc.).

9 En tanto profesional, este sujeto es el heredero histórico de un progreso técnico, de una formación y de una experiencia. En principio se forma dentro de una institución de la cual hereda tradiciones y creencias, luego se forma practicando su oficio -sin que esto neutralice los aportes de su formación-. Es productor de acciones que introducen transformaciones materiales de la realidad (gastar y utilizar energía y dinero, utilizar tecnologías, interactuar con otras personas, participar en la producción de riqueza y de valores de uso, la influencia sobre el modo de vida de personas que utilizan los artefactos que él ha concebido, etc.).

10 Como construcción teórica, el SD es siempre un objeto abstracto. Es un sistema complejo de conocimiento y de acciones, es un sistema auto-organizado. Para lograr sus fines, utiliza y coordina medios que le permiten realizar tareas de concepción, adaptándolas a diferentes situaciones. Estos medios son automatismos, conceptos y redes de conceptos de esquemas, razonamientos, creencias, métodos aprendidos en las escuelas o forjados por la experiencia, de algoritmos y heurísticas, de sistemas de valores, estrategias, sistemas de señales, habilidades técnicas, instrumentos cognitivos, imágenes o modelos mentales; de representaciones simbólicas, de fantasmas. Esta lista reagrupa globalmente los conocimientos tales como los definen diferentes enfoques cognitivos (Piaget, 1967; Le Ny, 1989; Rastier, 1991; Bachimont, 1992; Johnson-Laird, 1994; Hoc, 1996), pero también otros enfoques tales como la semiología y el psicoanálisis.

11 La puesta en evidencia de estos conocimientos y la descripción de la manera la cual el SD las utiliza, necesitan ser consideradas como 'entidades o actividades reales que tienen su propio nivel de existencia y de descripción' (Le Ny, 1989, p. 31). Una representación verbal, una imagen mental del concepto de 'belleza', la realización de un dibujo, el cálculo del volumen de los lados de una casa dibujada a mano, la utilización de calco, la simulación sobre una computadora de imágenes percibidas por un coche virtual al interior de un edificio que sólo existe como estado abstracto de un plano geométrico, la creencia según la cual el 'número de oro' es el mejor método de cálculo para obtener los reportes de proporción armónicas entre las diferentes partes de un edificio o de una luminaria, la planificación temporal de una tarea de concepción totalmente condicionada por un proyecto ergonómico, son diferentes formas empíricas de utilización de conocimientos.

12 El enfoque multidisciplinar de esta diversidad de conocimiento y campos de conocimiento, así como el de sus formas de aplicación, no revelan una empresa controvertida dirigida contra la pureza de las disciplinas, ni una búsqueda de originalidad, y aún menos, un ecumenismo epistemológico que reduciría su complejidad a un sistema de lugares comunes. La multidisciplinariedad es la primera en beneficiarse de la fertilidad heurística específica de cada disciplina.

13 No obstante, el enfoque multidisciplinar es diferente de aquel que propone cada disciplina de manera aislada. Primero, es adecuado a las realidades del trabajo humano (combinando, en sus formas empíricas, dimensiones históricas, sociales, tecnológicas, 
psicológicas, semiológicas, etc.). Luego, es susceptible de inspirar enriquecimientos críticos, así como clarificaciones múltiples al interior de cada disciplina. Por último, puede ayudar a situar y a redefinir ciertas complementariedades metodológicas que las disciplinas están en condiciones de ofrecer al análisis de las conductas humanas ${ }^{1}$.

El enfoque multidisciplinar permite definir la actividad del SD, bajo un ángulo a la vez cognitivo y semiológico. La actividad de un diseñador depende de un complejo de interacciones que corresponden a los diferentes polos dentro de una situación de concepción: tecnologías, tareas prescritas, otras personas, fuentes de conocimientos, las competencias del propio SD.

Esta última interacción (entre el SD y su propia competencia) permite definir al SD como una unidad de control relativamente autónoma, capaz de anticipar o de modificar, en función de los fines que él se fija, sus acciones y sus decisiones, al igual que la situación de concepción y su evolución. Para que estas interacciones sean finalizadas para la realización de un modelo de artefacto, el SD debe controlar los conocimientos espontáneos que le provee su propia competencia.

os principales referentes teóricos y metodológicos que han orientado los estudios de caso presentados en esta obra son fáciles de identificar: la epistemología genética, la psicología cognitiva, la lingüística y la semiología funcional, la didáctica, y también los modelos propuestos por la inteligencia artificial para formalizar los procedimientos de resolución de problemas y la didáctica.

Ellos son ampliamente completados por diferentes trabajos de la psicológica ergonómica (Leplat, 1993) y de la ergonomía cognitiva (Visser et Hoc, 1990; Falzon, Bisseret et al., 1990; Bonnardel, 1992; Visser, 1995; Darses, 1994; Meniru, Rivard, et Bédard, 2003) que han permitido clarificar y planificar la aplicación de estos conocimientos en terrenos empíricos de concepción.

18 Esta exploración de situaciones reales de concepción y este enfoque multidisciplinar no han podido lograr algunas de estas aclaraciones, todas centradas en la actividad cognitiva del sujeto-diseñador, todas centradas en la actividad cognitiva del sujetodiseñador, producto que siempre ha beneficiado de la colaboración y de las críticas de otros especialistas, en el marco colectivo de la investigación pública: docentes de la técnica y de las artes aplicadas, docentes de arquitectura, investigadores en psicológica ergonómica, expertos de revistas científicas, pero también de los actores concretos del diseño (técnicos, ingenieros, diseñadores profesionales, estudiantes en diseño).

Aunque la presentación de la situación de observación y su análisis tiende a acercar la actividad del observador-analista a la de un SD, como podrá darse cuenta el lector atento de esta obra, dicha comparación es limitada. El valor de un objeto físico en tres dimensiones diseñado por un especialista para satisfacer un uso social bien definido (automóvil, casa, imagen digital, radiocontrol de una grúa, computador, un par de zapatos, etc.) puede verificarse inmediatamente y de manera precisa, tan pronto como haya sido puesto en servicio. Este no es el caso de un modelo de la actividad de concepción entregada por un investigador en sus trabajos. Este libro se divide en cuatro etapas.

21 La primera ('Problemática, teoría y métodos'), se compone de cinco capítulos. Un primer capítulo describe el marco empírico construido y explorado para las necesidades del análisis: el SD, ubicado en el centro de un complejo de interacciones. En el segundo capítulo se definen los marcos teóricos que han permitido abordar la 
actividad cognitiva e individual de diseño, bajo un ángulo multidisciplinar. El tercer capítulo está consagrado a las representaciones producidas y manipuladas por el SD. Dos capítulos describen en detalle, los métodos de análisis de contenido aplicados sucesivamente a las verbalizaciones y a las crónicas de dibujos producidos por el SD. Estos métodos tienen como fin, extraer las representaciones producidas por el SD y sus dinámicas de producción, los rasgos esenciales de su actividad.

La segunda parte ('Desdoblamiento cognitivo, planificación, organización colectiva') está centrada sobre los medios de control y de regulación de la actividad de diseño desplegada por el SD. Cuatro capítulos restituyen los análisis detallados de actividades de arquitectos y de diseñadores industriales, bajo la forma de estudios de caso. El acento ha sido puesto en las similitudes y las diferencias entre arquitectura y diseño industrial. No obstante, la cuestión del control llevado a cabo por propio el SD sobre su actividad, es presentado en los dos dominios de diseño, al igual que las diferentes utilizaciones del dibujo que permiten a un arquitecto o a un diseñador, construir un modelo definido de artefacto. El dibujo aparece como el medio principal que posee el SD para controlar la incertidumbre y la precisión de las informaciones que definen el artefacto que él mismo diseña. Finalmente, un cuatro capítulo muestra cómo la organización colectiva del trabajo de concepción asegura al SD una parte esencial de los referentes de control y de regulación de su actividad, a través de la asistencia que le proporcionan los colaboradores, ellos mismos productores de una actividad de concepción y dominando diferentes sistemas informáticos de representación y de comunicación (sistemas CAO).

23 La tercera parte ('El SD, herencia del progreso técnico y de sus consecuencias organizacionales') muestra en tres capítulos cómo el progreso deslumbrante de las tecnologías de tratamiento y de comunicación de la información -y en particular aquellos realizados a través del diseño asistido por computador (CAO)-, han influenciado la actividad del SD, al igual que la organización colectiva dentro la cual se inscribe. El progreso técnico ha reforzado ostensiblemente la densidad y el dinamismo de la red sociotécnica en la cual el SD sortea una parte esencial de los medios de regulación de su actividad. Sin embargo, dos constataciones resultan de estas observaciones y análisis. Sean cuales fuesen estas nuevas condiciones de concepción, el dibujo manual sigue siendo una herramienta y una fase indispensable del diseño. Estos análisis muestran que la eficacia de la red de asistencia, que permite al SD de realizar sus modelos, depende de la experiencia de especialistas que conocen perfectamente las condiciones de realización material del artefacto a concebir.

Una cuarta y última parte ('los diseñadores en situación didáctica') reúne, en dos capítulos, los análisis de actividad de SD en período de formación inicial. El énfasis ha sido puesto sobre la importancia de la herencia histórica que transmiten los docentes, en su contribución a la construcción de una competencia de concepción. Las estrategias didácticas que consisten, para enseñantes, a privilegiar, la actividad cognitiva del estudiante a expensas de una reproducción sistemática de las prácticas profesionales, abren perspectivas concretas al rol que puede jugar la psicología, en el dominio del aprendizaje de los conocimientos de diseño, y, más 


\section{NOTAS}

1. Por ejemplo, el análisis de contenido de enunciados verbales o de dibujos, debe tener en cuenta las diferencias entre semántica inferencial y semántica referencial, entre el 'significado' según los lingüistas y el 'concepto’ definido por los psicológos (Lyions, 1978; Rastier, 1991). 